\title{
Evaluation of the Suspending Properties of the Co- precipitate of Irvingia gabonesis Gum and Gelatin
}

\author{
Sylvester O Eraga ${ }^{1 *}$, Magnus A Iwuagwu ${ }^{1}$ and Michael U Adikwu ${ }^{2}$ \\ ${ }^{1}$ Department of Pharmaceutics and Pharmaceutical Technology, Faculty of Pharmacy, University of Benin, PMB 1154, Benin \\ City 300001, ${ }^{2}$ Department of Pharmaceutics, Faculty of Pharmaceutical Sciences, University of Nigeria, Nsukka 410001, \\ Nigeria
}

*For correspondence: Email: eragaso@uniben.edu; Tel: +2348030884928

\begin{abstract}
Purpose: To evaluate the suspending properties of the co-precipitate from Irvingia gabonensis gum variety Excelsa (Fam: Irvingiaceae) and gelatin.

Methods: The gum from Irvingia gabonensis was extracted and co-precipitated with gelatin in gum/gelatin ratios of 1:1, 1:2, 1:3, 1:4, 1:0 and 0:1. The suspending ability of the different ratios was evaluated in magnesium trisilicate suspension, and compared with a suspension prepared with Compound Tragacanth Powder BP (CTP) as well as a commercially available magnesium trisilicate suspension (MTS). The parameters tested were sedimentation rate, flow rate, viscosity, and $\mathrm{pH}$. The effect of mono- and divalent electrolytes on the sedimentation rate of the suspensions was also studied. Results: In terms of suspending ability, co-precipitated gum-gelatin ratio of 1:2 was comparable to CTP while gum-gelatin ratio 1:3 was a superior suspending agent than CTP with regard to the parameters determined. At $2 \% w / v$ concentration, the suspending ability of the suspending agents were in the rank order: 1:4 $>1: 3>1: 2>C T P>1: 1>1: 0>$ MTS $>0: 1$. The 1:3 ratio suspensions also exhibited good stability following addition of mono- and divalent electrolytes although there was significant $(p>0.05)$ reduction in sedimentation volume.

Conclusion: It can be inferred from the results of this investigation that the suspension prepared with the co-precipitate of Irvingia gabonensis gum and gelatin as a suspending agent appears to be superior to those prepared with the gum or gelatin alone as well as MTS.
\end{abstract}

Keywords: Irvingia gabonensis, Gum, Gelatin, Co-precipitate, Suspending agent, Stability, Magnesium trisilicate, Electrolytes

Tropical Journal of Pharmaceutical Research is indexed by Science Citation Index (SciSearch), Scopus, International Pharmaceutical Abstract, Chemical Abstracts, Embase, Index Copernicus, EBSCO, African Index Medicus, JournalSeek, Journal Citation Reports/Science Edition, Directory of Open Access Journals (DOAJ), African Journal Online, Bioline International, Open-J-Gate and Pharmacy Abstracts

\section{INTRODUCTION}

A suspension is a two-phased system in which a finely divided solid is dispersed in a continuous phase of solid, liquid or gas. The undissolved solid exists in equilibrium with a saturated solution of the solid in the continuous phase [1]. There are two main reasons for formulating drugs into suspension [2], viz, poorly soluble or indiffusible drugs formulated as suspensions and enhancing the stability of drugs that are not stable in aqueous medium. Drugs in suspension are more readily bioavailable than drugs in tablet or capsule dosage form [3]. Suspensions have a number of drawbacks such as rapid settling of dispersed particles, particle size growth and caking. To ameliorate these drawbacks, a stabilizer or suspending agent is normally incorporated in the dosage form. Natural gums like acacia, trgacanth, khaya, karaya and albizia are examples of polysaccharides used as suspending agents [4]. 
Co-precipitation is the simultaneous precipitation of a soluble component with a macro-component from the same solution by the formation of mixed crystals, by adsorption, occlusion or mechanical entrapment [5]. The aim of co-precipitation, e.g., polymer-polymer interaction, is to produce a stable polymer with better properties than the individual polymers.[6] Co-precipitation which is an example of solid dispersion is a recognized technique for increasing the dissolution of poorly water-soluble drugs so as to improve their bioavailability [7].

Irvingia gabonensis (Fam. Irvingiaceae) popularly known as "Dika nut" is a tropical plant with two varieties (excelsa and gabonensis) [8,9]. The seed of the plant contains lipids and polymeric constituents $[10,11]$. Its products are of varied pharmaceutical uses and include Dika wax and Dika fat [12]. The mucilage of its kernel has been investigated as a tablet binder, an emulsifying agent and a suspending agent in pharmaceuticals $[13,14]$. Suspensions may be prepared using several gums, either alone or in combination with other gums. When two gums are co-precipitated, their ability to suspend a drug tends to increase more than their individual abilities. This work sought to evaluate the suspending properties of the co-precipitate of Irvingia gabonensis gum and gelatin as an alternative to a conventional suspending agent in suspension formulations.

\section{EXPERIMENTAL}

The following chemicals were procured from a supplier and used without further purification: acetone and benzoic acid were analytical reagent from $\mathrm{BDH}$ Chemicals, UK, magnesium trisilicate powder, Compound Tragacanth Powder BP, gelatin (Type B) (Merck, Germany). Water was double distilled. Magnesium trisilicate suspension was received courtesy of Nomagbon Pharmaceutical Ltd, Benin City, Nigeria. Irvingia gabonensis seeds were collected in the month of May and identified by Mr. Sunday Nweke of the Department of Pharmacognosy, University of Benin, Nigeria. A voucher specimen (UBH_I0153) of the seed has been kept in the herbarium of the Department of Plant Biology and Biotechnology, University of Benin, Nigeria, for future reference.

\section{Extraction of Irvingia gabonensis gum}

About $400 \mathrm{~g}$ of Irvingia gabonensis seeds was weighed and the outer coat was removed with the aid of a razor blade. The hard milky cotyledons were dried at $60{ }^{\circ} \mathrm{C}$ in a hot air oven
(Kottermann) for $3 \mathrm{~h}$, pulverized in an end-runner mill (Pascall, England) and passed through a sieve with a mesh size of $0.300 \mathrm{~mm}$. The resulting powder was cream coloured and sticky with a pleasant odour.

Extraction of the gum was carried out according to Momoh et al [15]. About $300 \mathrm{~g}$ of the powdered cotyledon was dispersed in $4 \mathrm{~L}$ of distilled water in a plastic container. The dispersion was homogenized for about $1 \mathrm{~h}$ and left for $24 \mathrm{~h}$. The mucilage formed was then filtered through a clean muslin cloth to obtain a viscous filtrate (gum). The filtrate was subjected to a number of washings with acetone until it was no longer slippery to touch in order to remove all traces of its fat components. The gum was then dried in a desiccator for 3 days, pulverized and then passed through a sieve of mesh size, 0.365 $\mathrm{mm}$. The resulting powder was kept in an airtight container until used.

\section{Preparation of co-precipitate of gelatin and Irvingia gabonensis}

The co-precipitate of gelatin and Irvingia gabonensis gum was formed by dissolving the gelatin and gum in warm water. The solutions of the gum and gelatin were then mixed together with constant stirring. The mixed gum-gelatin solution was then poured into a solution of acetone and stirred until the co-precipitate was formed. The co-precipitate was filtered and dried in a desiccator for 3 days after which it was pulverized into powder and stored in an air-tight container. The gum-gelatin ratios were; $1: 1 ; 1: 2$, $1: 3,1: 4,1: 0$ and $0: 1$.

\section{Formulation of magnesium trisilicate suspension}

The suspensions were formulated in accordance with the BP formula. A $200 \mathrm{ml}$ of the suspension was prepared; $4 \mathrm{~g}$ of the magnesium trisilicate powder was finely powdered and mixed intimately with $4 \mathrm{~g}$ of the co-precipitated (ratio 1:1) in a mortar. Benzoic acid (1 g) was dissolved in $10 \mathrm{ml}$ of warm water and added to the magnesium trisilicate-gum mixture and triturated together to form a smooth paste. The mixture was quantitatively transferred into a $200 \mathrm{ml}$ tared bottle and the volume made up to mark with distilled water and then shaken vigorously for 2 min (thus making $2 \% \mathrm{w} / \mathrm{v}$ of the co-precipitated gum in the preparation). The same procedure was repeated for ratios $1: 2,1: 3,1: 4,1: 0,0: 1$.and compound tragacanth powder BP. 


\section{Determination of sedimentation volume}

The sedimentation volume was determined by placing $50 \mathrm{ml}$ of each suspension in a stoppered measuring cylinder and stored undisturbed at room temperature of $28 \pm 2{ }^{\circ} \mathrm{C}$. The separation of clear liquid was noted at intervals for 7 days. The sedimentation volume was calculated using the formula $\mathrm{Vu} / \mathrm{Vo}$, where $\mathrm{Vu}$ is the volume of sediment and $\mathrm{Vo}$ is the original height of the sample [16].

\section{Determination of flow rate}

The time required for each suspension sample to flow through a $10 \mathrm{ml}$ pipette at room temperature was determined and the flow rate (apparent viscosity, na) was calculated as in Eq 1.

Flow rate $(n \alpha)=\mathrm{Vp} / \mathrm{Tf}$

where $\mathrm{Vp}$ is the volume of the pipette $(\mathrm{ml})$ and $\mathrm{Tf}$ is flow time (s)

\section{Assessment of redispersion behaviour of suspensions}

A fixed volume of the suspensions $(50 \mathrm{ml})$ was kept in stoppered measuring cylinders which were stored at room temperature. One cylinder was removed each day and shaken vigorously to redisperse the sediment and the presence of deposit, if any was recorded.

\section{Evaluation of viscosity of suspensions}

A torsion viscometer was used to determine the viscosity of the different suspensions at room temperature. The suspension $(50 \mathrm{ml})$ was poured into a small rubber bowl. The ball-like spindle was then lowered into the suspension so as to touch the suspension. The ball was then released and allowed to rotate, at the end of which the reading was taken.

\section{Determination of $\mathrm{pH}$ of suspensions}

The $\mathrm{pH}$ of the suspensions was determined in triplicates using a digital $\mathrm{pH}$ meter $(\mathrm{HI} 2215$, Hanna Instruments, USA).

\section{Evaluation of effect of electrolytes on suspension stability}

About $10 \mathrm{ml}$ of 1 or $2 \%$ concentration of monovalent $(\mathrm{NaCl})$ and divalent $\left(\mathrm{CaCl}_{2}\right)$ electrolytes were added to $40 \mathrm{ml}$ of the suspension and their sedimentation parameters (Vo and $\mathrm{Vu}$ ) recorded at intervals over 7 days;
$\mathrm{Vo}$ and $\mathrm{Vu}$ are the initial and final volumes of sediment, respectively. This was carried out for the gum-gelatin suspension of ratio $1: 3$ and the values were compared with the values of the same sample without electrolyte. This evaluation was carried out in triplicates.

\section{Statistical analysis}

Statistical evaluation was done by one-way analysis of variance (ANOVA) at a significant level of $p<0.05$ by Dunnett's multiple comparison test using GraphPad InStat software version 3.10 .

\section{RESULTS}

All the magnesium trisilicate suspensions prepared were off-white in color with a pleasant odour. The sedimentation volume profiles of the suspensions formulated with varying gum-gelatin ratios and compound tragacanth powder $\mathrm{BP}$, as well as the commercial magnesium trisilicate suspension are shown in Figure 1. The sedimentation volumes (Table 1) of all the suspensions formulated with the different ratios of the gum-gelatin were not comparable with each other and the commercial magnesium trisilicate suspension. The 1:2 gum-gelatin ratio suspension was comparable to the suspension stabilized with compound tragacanth gum. There were significant differences $(p<0.05)$ in the sedimentation volume of ratios 1:4, 0:1 and the commercial magnesium trisilicate suspension when compared with compound tragacanth powder BP. The sedimentation volume and viscosity (Table 2) of the suspensions show a direct relationship with increase in the concentration of the gelatin in the co-precipitate and an inverse relationship with regard to their flow rate (Table 2). All the suspensions were found to be readily redispersible except that made with a gum-gelatin ratio of $1: 4$, which was very difficult to redisperse even with vigorous agitation. The $\mathrm{pH}$ of the suspensions formulated with the varying ratios of the gum-gelatin coprecipitate was acidic (Table 2). Both the compound tragacanth gum stabilized suspension and the commercial magnesium trisilicate suspension had an alkaline $\mathrm{pH}$.

Figure 2 shows the effect of the different concentrations of the monovalent and divalent electrolytes on the sedimentation parameters of the suspension prepared with a ratio of $1: 3$ of Irvingia gabonensis gum and gelatin. The addition of these electrolytes decreased the 


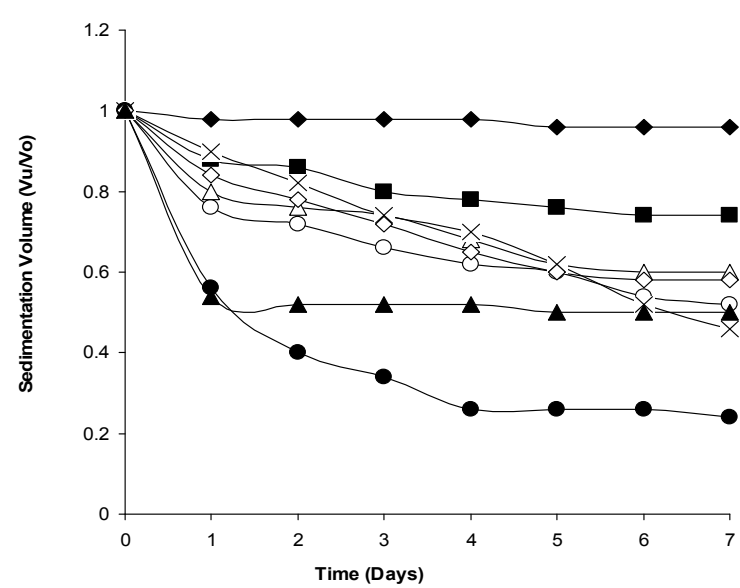

Figure 1: Sedimentation profiles of suspensions made with different ratios of Irvingia gabonensis gum and gelatin, compound tragacanth powder BP (CTP) and the commercial magnesium trisilicate suspension

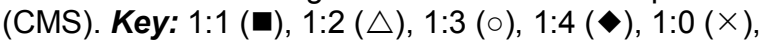
$0: 1(\bullet), \operatorname{CTP}(\diamond), \operatorname{CMS}(\mathbf{\Delta})$

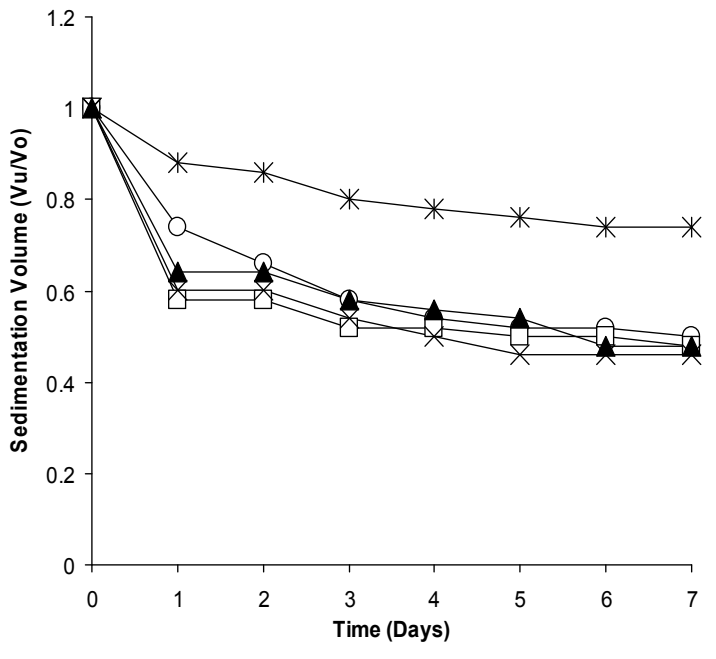

Figure 2: Effect of electrolyte on the sedimentation profile of suspension made with Irvingia gabonensis gum/gelatin ratio of $1: 3$. Key: $1 \% \mathrm{NaCl}(0), 2 \% \mathrm{NaCl}$ (口), $1 \% \mathrm{CaCl}_{2}(\mathbf{\Delta}), 2 \% \mathrm{CaCl}_{2}(\times), 0 \%$ (*, Control)

Table 1: Sedimentation volume of suspensions

\begin{tabular}{lcccccccccc}
\hline Suspending agent & & \multicolumn{8}{c}{ Sedimentation volume } \\
\cline { 3 - 10 } $\begin{array}{l}\text { Gum/gelatin } \\
\text { ratio }\end{array}$ & $\begin{array}{c}\text { Conc. } \\
\text { (\%w/v) }\end{array}$ & $\mathbf{0}$ & $\mathbf{1}$ & $\mathbf{2}$ & $\mathbf{3}$ & $\mathbf{4}$ & $\mathbf{5}$ & $\mathbf{6}$ & $\mathbf{7}$ \\
\hline $1: 1$ & 2 & 1 & 0.76 & 0.72 & 0.66 & 0.62 & 0.60 & 0.54 & 0.52 \\
$1: 2$ & 2 & 1 & 0.80 & 0.76 & 0.74 & 0.68 & 0.62 & 0.60 & 0.60 \\
$1: 3$ & 2 & 1 & 0.88 & 0.86 & 0.80 & 0.78 & 0.76 & 0.74 & 0.74 \\
$1: 4$ & 2 & 1 & 0.98 & 0.98 & 0.98 & 0.98 & 0.96 & 0.96 & 0.96 \\
$1: 0$ & 2 & 1 & 0.90 & 0.82 & 0.74 & 0.70 & 0.62 & 0.52 & 0.46 \\
$0: 1$ & 2 & 1 & 0.56 & 0.40 & 0.34 & 0.26 & 0.26 & 0.26 & 0.24 \\
CTP & 2 & 1 & 0.84 & 0.78 & 0.72 & 0.65 & 0.60 & 0.58 & 0.58 \\
CMS & 0 & 1 & 0.54 & 0.52 & 0.52 & 0.52 & 0.50 & 0.50 & 0.50 \\
\hline
\end{tabular}

Note: CTP = Compound Tragacanth Powder BP; CMS = commercial magnesium trisilicate

Table 2: Viscosity and $\mathrm{pH}$ of suspensions

\begin{tabular}{lcccccc}
\hline $\begin{array}{l}\text { Amount of } \\
\text { gum }(\mathbf{g})\end{array}$ & $\begin{array}{c}\text { Amount of } \\
\text { gelatin }(\mathbf{g})\end{array}$ & Ratio & $\begin{array}{c}\text { Concentration } \\
(\% \mathbf{w} / \mathbf{v})\end{array}$ & $\begin{array}{c}\text { Flow rate } \\
\left(\mathbf{m l ~ s}^{-1}\right)\end{array}$ & $\begin{array}{c}\text { Viscosity } \\
(\text { poises })\end{array}$ & pH \\
\hline 2 & 2 & $1: 1$ & 2 & 1.25 & 1.75 & 4.64 \\
2 & 4 & $1: 2$ & 2 & 1.10 & 1.92 & 4.45 \\
2 & 6 & $1: 3$ & 2 & 0.90 & 2.20 & 4.47 \\
2 & 8 & $1: 4$ & 2 & - & 2.55 & 4.40 \\
4 & 0 & $1: 0$ & 2 & 1.45 & 1.10 & 4.70 \\
0 & 4 & $0: 1$ & 2 & 1.65 & 0.55 & 5.83 \\
Suspension with CTP & & & 2 & 1.20 & 1.80 & 8.20 \\
CMS & & & 0 & 1.85 & 0.10 & 8.50 \\
\hline
\end{tabular}

Note: CTP = Compound Tragacanth Powder BP; CMS = commercial magnesium trisilicate

sedimentation volume of the suspensions to a significant level $(p<0.05)$ with the control. Though the higher concentration of the electrolytes had a greater effect on the sedimentation volume, this effect was not significant $(p>0.05)$ when the electrolytes were compared. The decrease in sedimentation volume can only be seen in the first $24 \mathrm{~h}$ of storage. The sedimentation volume levels out after $24 \mathrm{~h}$ with little or no change thereafter (Table 3). 
Table 3: Effect of electrolyte on the sedimentation volume of suspensions prepared with 1:3 coprecipitate of Irvingia gabonensis gum and gelatin

\begin{tabular}{lccccc}
\hline \multirow{2}{*}{ Days } & \multicolumn{3}{c}{ Sedimentation volume } \\
\cline { 2 - 6 } & $\mathbf{1 \%}$ & $\mathbf{2 \%}$ & $\mathbf{1 \%}$ & $\mathbf{2 \%}$ & $\mathbf{0 \%}$ \\
\hline 1 & 0.74 & 0.58 & 0.64 & 0.60 & 0.88 \\
2 & 0.66 & 0.58 & 0.64 & 0.60 & 0.86 \\
3 & 0.58 & 0.52 & 0.58 & 0.54 & 0.80 \\
4 & 0.54 & 0.52 & 0.56 & 0.50 & 0.78 \\
5 & 0.52 & 0.50 & 0.54 & 0.46 & 0.76 \\
6 & 0.52 & 0.50 & 0.48 & 0.46 & 0.74 \\
7 & 0.50 & 0.48 & 0.48 & 0.46 & 0.74 \\
\hline \multicolumn{7}{l}{ Control $=0 \%$ electrolyte } \\
\multicolumn{7}{c}{}
\end{tabular}

\section{DISCUSSION}

On the whole, the suspension prepared with gum-gelatin co-precipitate ratio of $1: 3$ gave the best properties of an ideal suspension, such as; slow sedimentation rate, elegance, pourability and redispersibilty. Its sediment was in a flocculated state. Its viscosity value would also suggest that the ratio is the optimum concentration of the gum and gelatin that would give good suspending properties. The suspension formulated with 1:4 gum-gelatin ratio had very slow sedimentation rate however, there was difficulty in pouring and redispersing the suspension. These properties may suggest the possibility of cake formation if the suspension is stored over a long period of time. A pharmaceutically acceptable suspension produces sediment on storage, but the sediment must be readily redispersed so as to ensure uniformity of dispensed doses. If sediment remains even after vigorous agitation, the system may be described as caked.

The result shows that the co-precipitate (Irvingia gabonensis gum and gelatin) is acidic. The use of the co-precipitate as a suspending agent in drug formulation has to take into account this acidic nature to avoid possible interactions with formulated medicaments and exacerbation of some health conditions like hyperacidity.

Also, the minimal effect of the added electrolyte to the suspension (ratio 1:3) in the first $24 \mathrm{~h}$ and thereafter remaining unchanged suggest that the co-precipitate (Irvingia gabonensis gum and gelatin) as a stabilizing agent can withstand minimal changes in $\mathrm{pH}$ which can result from the addition of formulation excipients with a view to improving the suspension palatability and aesthetics.

\section{CONCLUSION}

The results obtained indicate that the suspension stabilized with Irvingia gabonensis gum/gelatin co-precipitate ratio of $1: 3$ is the most satisfactory of all the suspensions. The suspension was stable, even in the presence of mono- and divalent electrolytes. However, further studies are required to determine the suitability of the coprecipitate when used in large-scale production of suspensions.

\section{REFERENCES}

1. Billany M. Suspension and emulsion. In Aulton ME, Ed. Aulton's Pharmaceutics - The Science of Dosage Form Design, Churchill Livingston, Spain; 2007. Chap 23; pp 383-405.

2. Ofoefule SI. Suspensions: In: Pharmaceutical Technology and Industrial Pharmacy. Samakin, Nigeria; 2002; pp 129-178.

3. Ali Y, Kimura A, Martin J. Coffey MJ, Tyle $P$. Pharmaceutical Development of Suspension Dosage Form. In: A.K. Kulshreshtha et al. eds. Pharmaceutical Suspensions: From Formulation Development to Manufacturing, Springer New York. 2010; $p 104$.

4. Trease GE, Evans WC. Pharmacognosy. 4th edn, W.B. Sounders, USA; 1996. pp 196-210.

5. Battista OA. Colloidal polymer microcrystals: New composition for cosmetics. J Soc Cosmet Chem 1971; 22: 561-569.

6. Wu S. Interfacial energy, structure and adhesion between polymers. In: Paul Dr. Newman S. ed., Polymer Blends, Vol. I. New York. Academic Press; 1978; pp 243-293.

7. Adikwu MU, Yoshikawa Y, Takada K. Bioadhesive delivery of metformin using prosopis gum with antidiabetic potential. Biol Pharm Bulletin 2003; 26 (5): $662-666$.

8. Anil KS. Bush mango (Irvingia gabonensis): New potential multipurpose fruit tree for India. Plant Genet Resour 2007; 20(1): 32-37.

9. Okafor JC, Okolo HC. Potentials of some indigenous fruit trees of Nigeria. Paper presented at the 5th Annual Conference of the Forestry Association of Nigeria, December, 1974, Jos, Nigeria.

10. Eka OU. Proximate composition of bush mango tree and some properties of dika fat. Niger J Nutr Sci 1980; 1: 33-36.

11. Ndjouenkeu R, Akingbala J, Oguntimein G. Emulsifying properties of three African food hydrocolloids: Okra (Hibiscus esculentus), dika nut (Irvingia gabonensis), and khan (Belschmiedia sp.). Plant Foods Hum Nutr 1997; 51: 245-55.

12. Megwa SA. Evaluation of dika fat as a suppository base. Drug Dev Ind Pharm 1987; 13 (15): 2731-2748. 
13. Isimi $C Y$, Kunle OO, Bangudu $A B$. Some emulsifying and suspending properties of the mucilage extracted from kernels of Irvingia gabonensis. Boll Chim Farm 2000; 139 (5): 199-204.

14. Odeku OA, Patani BO. Evaluation of dika nut mucilage (Irvingia gabonensis) as binding agent in metronidazole tablet formulations. Pharm Dev Technol 2005; 10 (3): 439-446.
15. Momoh MA, Ogbonna JI, Nwachi UE, Ibezim EC. Suspension properties of binary mixtures of tragacanth gum and Irvingia gabonensis gum. Plant Prods Res 2008; 12:1-3.

16. Martin A. In: Physical Pharmacy. 4th edn, Lippincott William and Wilkins, Baltimore, USA; 2001; pp 480481. 